\title{
The Keto Acid Metabolism of Corynebacterium diphtheriae growing in Submerged Culture
}

\author{
By D. C. EDWARDS \\ Wellcome Research Laboratories (Biological Division), Langley Court, \\ Beckenham, Kent
}

(Received 21 April 1960)

SUMMARY

The keto acid production of Corynebacterium diphtheriae (strain CN 2000) growing in submerged culture in complex medium was investigated. Pyruvic acid production followed a pattern in which there was a very rapid production of acid which reached a peak about $12 \mathrm{hr}$. after inoculation. The acid concentration decreased rapidly after $12 \mathrm{hr}$. and the final pyruvic acid concentration appeared to be very variable. The source of the pyruvic acid is believed to be lactic acid, the concentration of which decreased rapidly as pyruvic acid increased. The presence in the medium of sufficient iron to abolish toxin production completely did not affect the pattern of pyruvic acid production. $\alpha$-Ketoglutaric acid production in the cultures appeared to vary in a random manner. $C$. diphtheriae strain G12/6 produced a maximum yield of pyruvic acid after only $6 \mathrm{hr}$. growth but was otherwise similar to strain CN2000. C. diphtheriae strain SM1 gave a maximum production of pyruvic acid after $24 \mathrm{hr}$. but in the presence of $3 \mu \mathrm{g}$. Fe/ml. production was more rapid and was like that found for strain $\mathrm{CN} 2000$. No correlation was found between toxin production and the production of pyruvic acid or $\alpha$-keto glutaric acid.

\section{INTRODUCTION}

In 1958 Yoneda \& Ishihara showed that when they grew the SM1 strain of Corynebacterium diphtheriae in static culture for 4 days at $32-\mathbf{3 3}^{\circ}$ the addition of increasing amounts of iron to the culture inhibited the formation of toxin and of pyruvic acid. This seemed to be one of the few if not the only instance of a direct relationship between toxin production and a metabolite which had been reported for this organism, and it was decided to investigate the keto acid metabolism of various strains of $C$. diphtheriae growing in a stirred and aerated culture of the type described by Linggood, Matthews, Pinfield, Pope \& Sharland (1955).

\section{METHODS}

Organisms. Three strains of Corynebacterium diphtheriae were used: CN2000 (the Wellcome Research Laboratories Culture Collection); G12/6 supplied by Dr G. D. Clarke; SM 1 supplied by Dr M. Yoneda. In each case a 24 hr. growth on a Loeffler slope was used to inoculate $200 \mathrm{ml}$. medium in a $1000 \mathrm{ml}$. Erlenmeyer flask. 
The flask was placed on a rotary shaker in an incubator at $35^{\circ}$ and shaken for $24 \mathrm{hr}$. after which time the culture was used to inoculate the tank.

Culture vessels and medium. Tanks (20 l.) were used as described by Edwards \& Seamer (1960) and contained papain digest of beef (11 1.; Ramon, Pochon \& Amoureux, 1941) which had been treated with yeast (Pope \& Smith, 1932) and to which $0.5 \%(\mathrm{v} / \mathrm{v})$ glacial acetic acid and $2.4 \%(\mathrm{w} / \mathrm{v})$ maltose were added. Antifoam A (Midlands Silicone Ltd., Upper Brook Street, London) dispersed in butyl acetate was added ( $15 \mathrm{ml} .25 \%$, w/v); air was passed through the tanks (at $500 \mathrm{ml} . / \mathrm{min}$.); the temperature was maintained at $35^{\circ}$ and the cultures incubated for $48 \mathrm{hr}$.

Keto acid estimations. Estimations of pyruvic acid and of $\alpha$-ketoglutaric acid were carried out by a chromatographic method (Cavallini \& Frontali, 1954; Cavallini \& Mandovi, 1957). The solvent used was a mixture of $n$-butanol, ethanol and $0.5 \mathrm{~N}$-ammonia $(70+10+20$, El Hawary \& Thomson, 1953). Besides pyruvic acid and $\alpha$-ketoglutaric acid two other keto acid hydrazones were normally found on the chromatograms (see Jännes, 1954). Since these were unidentified and the pattern of their production was in no way noteworthy they are not further discussed in this paper. On a few occasions a spot corresponding to oxaloacetic acid was also found.

Lactic acid estimations. These were carried out by the method of Barker \& Summerson (1941). Since the samples were known to contain large amounts of keto acids, the deproteinized material was treated with 2:4-dinitrophenyl hydrazine and then extracted with benzene before the usual copper sulphate and calcium hydroxide treatment.

Toxin. This was estimated by the flocculation method (Ramon, 1922; Glenny \& Okell, 1924). Results are expressed as Lf units/ml. (Lf/ml.).

\section{RESULTS}

Experiments with strain CN 2000. Since strain CN 2000 of Corynebacterium diphtheriae is the one in use for the routine production of high titre diphtheria toxin at these laboratories it was the one most studied. In all, nine complete analyses were performed in which samples were analysed every $6 \mathrm{hr}$. during the whole $48 \mathrm{hr}$. of the incubation period; three of the cultures contained sufficient iron to give complete inhibition of toxin production. The results were subject to variation but in most cases curves of the type shown in Fig. 1 were obtained. Pyruvic acid was produced with great rapidity and by the 12 th $\mathrm{hr}$. concentrations higher than $600 \mu \mathrm{g}$. $/ \mathrm{ml}$. were common. This period of production was usually followed by a period of rapid disappearance of the acid. The variations in production were of two types. In the first the height of the peak was much lower than usual (c. $300 \mu \mathrm{g}$.) $\mathrm{ml}$.) and in the second the disappearance of pyruvic acid was relatively slow. Figure 1 also shows the production of $\alpha$-ketoglutaric acid. It was very variable in the cultures studied and in the examples in Fig. 1 the final $\alpha$-keto glutaric acid concentrations after $48 \mathrm{hr}$. growth were 30 and $304 \mu \mathrm{g} . / \mathrm{ml}$. and the corresponding toxin titres were 345 and $305 \mathrm{Lf} / \mathrm{ml}$.

It seemed possible that the source of the pyruvic acid in the cultures might be lactic acid. Tank contents were analysed and the results obtained during the first $24 \mathrm{hr}$. are shown in Fig. 2. The interpretation of this seems clear. Lactic acid, 
present in the medium and presumably derived from the beef used in the preparation of the medium, was rapidly converted to pyruvic acid which was then further metabolized and perhaps partially converted back to lactic acid. The disappearance of the pyruvic acid is complicated by the fact that metabolism, presumably via acetate and the tricarboxylic acid cycle, will also be occurring and thus the sum of lactic and pyruvic acids, which in the very early stages of growth is sensibly constant, showed a marked decline.

Since Yoneda \& Ishihara (1958) had shown an effect of iron on pyruvate formation it might have been anticipated that the presence of enough iron to inhibit toxin production completely would also exert a marked effect on pyruvic acid metabolism. The results shown in Fig. 3 show that this was not the case. The two curves differ only in the amount of pyruvic acid found after $12 \mathrm{hr}$., the pattern

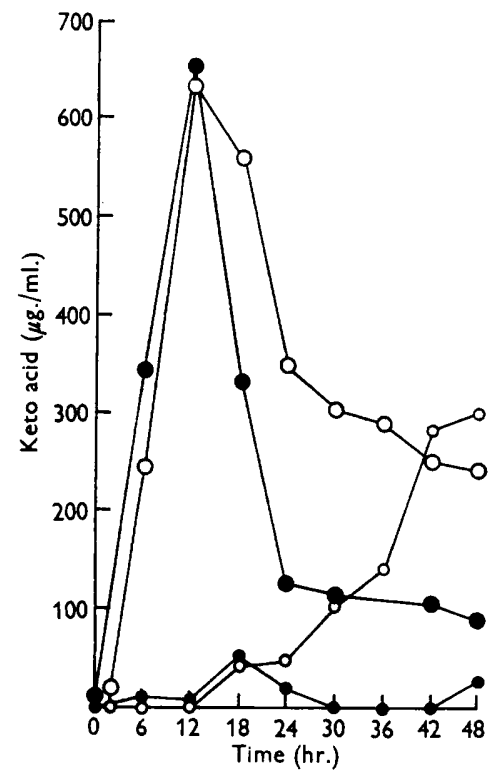

Fig. 1

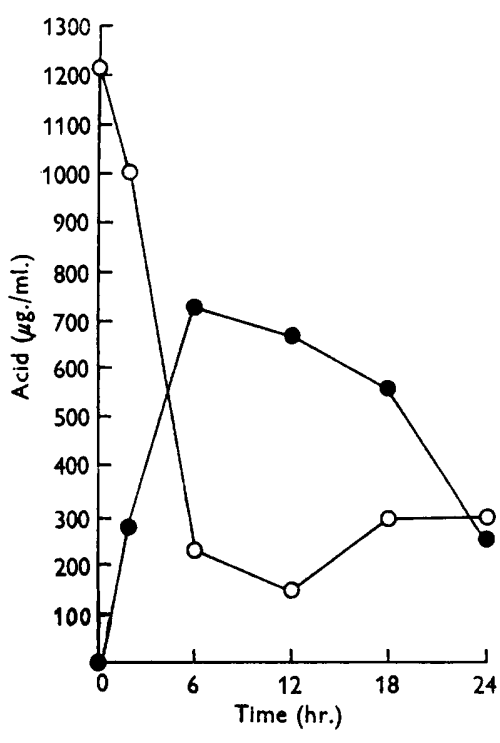

Fig. 2

Fig. 1. Keto acid production in two cultures of the $\mathrm{CN} 2000$ strain of Corynebacterium diphtheriae. The $0 \mathrm{hr}$. samples were uninoculated medium. SC $12720-0$, pyruvic acid; $\circ-0, \alpha$-ketoglutaric acid. SC $1257 \bullet-\bullet$, pyruvic acid; $\bullet-, \alpha$-ketoglutaric acid.

Fig. 2. Lactic acid and pyruvic acid in a culture (SC 1597) of the CN2000 strain of Corynebacterium diphtheriae. The $0 \mathrm{hr}$. sample was uninoculated medium. $\mathrm{O}-\mathrm{O}$, lactic acid; - pyruvic acid.

of metabolism remaining unchanged. Since the toxin yields produced by the two cultures were 340 and $0 \mathrm{Lf} / \mathrm{ml}$., it is clear that pyruvic acid metabolism and toxin production were not closely linked, at least with the CN2000 strain.

This is further borne out by the results in Table 1 in which analyses of $48 \mathrm{hr}$. cultures are shown arranged in order of descending $L f$ values. It is clear from Table 1 that neither the $\alpha$-ketoglutaric acid values nor the pyruvic acid values bear any relationship direct or indirect to the toxin titres. The extreme variability of the amounts of $\alpha$-ketoglutaric acid that were found is an indication of the lack 


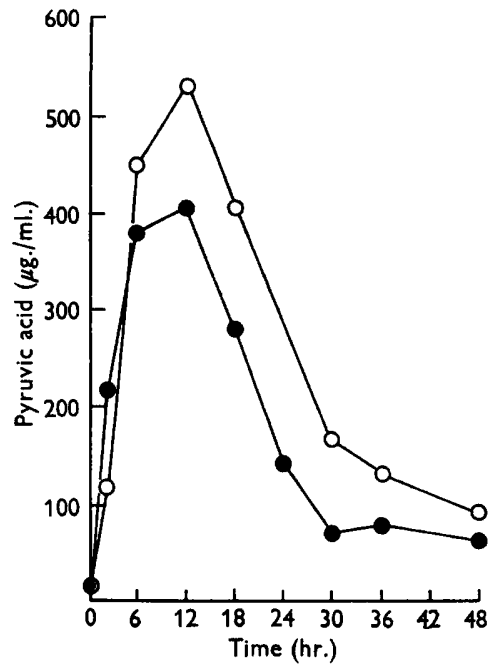

Fig. 3

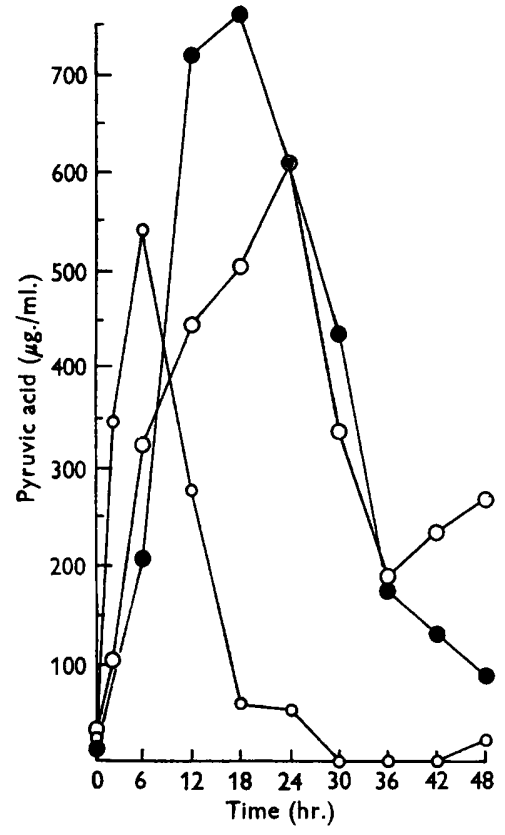

Fig. 4

Fig. 3. Pyruvic acid production by the CN2000 strain of Corynebacterium diphtheriae with and without added iron. The $0 \mathrm{hr}$. sample was uninoculated medium. $0-0$, no added iron; - - $4 \mu \mathrm{g}$. Fe/ml. added.

Fig. 4. Pyruvic acid production by the G12/6 strain of Corynebacterium diphtheriae without added iron and by the SM 1 strain with and without added iron. The $0 \mathrm{hr}$. samples

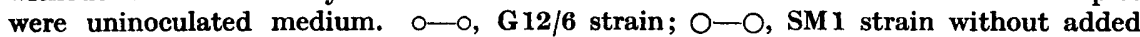
iron; - - SM 1 strain with $3 \mu \mathrm{g}$. Fe/ml. added.

Table 1. Analyses of $48 \mathrm{hr}$. cultures of Corynebacterium diphtheriae for toxin, pyruvic acid and $\alpha$-ketoglutaric acid

$\begin{array}{rcrr}\begin{array}{r}\text { Culture } \\ \text { number }\end{array} & \begin{array}{c}\text { Toxin } \\ (\text { Lf } / \text { ml. })\end{array} & \begin{array}{c}\text { Pyruvic acid } \\ (\mu \mathrm{g} . / \mathrm{ml} .)\end{array} & \begin{array}{r}\alpha \text {-ketogluta } \\ \text { acid }(\mu \mathrm{g} . / \mathrm{m}\end{array} \\ \text { SC 1257 } & 345 & 90 & \mathbf{3 0} \\ 1346 & 340 & 96 & 0 \\ 1440 & 328 & 408 & 8 \\ 1394 & 316 & 142 & 0 \\ 1391 & 312 & 98 & 0 \\ 1272 & 305 & 242 & 304 \\ 1438 & 296 & 258 & 0 \\ 1444 & 280 & 49 & 0 \\ 1442 & 275 & 78 & 0 \\ 1280 & 263 & 442 & 518 \\ 1331 & 262 & 12 & 0 \\ 1441 & 244 & 188 & 0 \\ 1393 & 236 & 187 & 65 \\ 1439 & 216 & 122 & 100 \\ 1249 & 202 & - & 646 \\ 1443 & 175 & 0 & 0 \\ 1389 & 170 & 158 & \end{array}$


of control over the organism that existed in this work although the conditions of cultivation were kept as uniform as possible. Even when the peak values for pyruvic acid (occurring after $12 \mathrm{hr}$. growth) are used there is still no apparent relationship to the final toxin yield, for in five cultures in which final ( $48 \mathrm{hr}$.) toxin titres of 202 , $263,305,340$, and $345 \mathrm{Lf} / \mathrm{ml}$. were found, the $12 \mathrm{hr}$. values for pyruvic acid were $300,710,637,536$ and $654 \mu \mathrm{g} . / \mathrm{ml}$, respectively.

Experiments with the $G 12 / 6$ and $S M 1$ strains. Figure 4 shows the production of pyruvic acid by the $\mathrm{G} 12 / 6$ and SM 1 strains. In the case of strain $\mathrm{G} 12 / 6$ the results were very similar to those found with strain $\mathrm{CN} 2000$ although the peak production occurred after only $6 \mathrm{hr}$. instead of $12 \mathrm{hr}$. as is usual with strain CN2000. The SM 1 strain when grown without any additional iron gave a relatively slow production of pyruvic acid which continued until $24 \mathrm{hr}$. after inoculation. In the presence of iron $(3 \mu \mathrm{g} . / \mathrm{ml}$.) the toxin production was nil (compared with $100 \mathrm{Lf} / \mathrm{ml}$. in the control) and the production of pyruvic acid rapid, reaching a peak after $12 \mathrm{hr}$. Disappearance of pyruvic acid started after $18 \mathrm{hr}$. and was rapid. Thus in the presence of iron, pyruvic acid production by strain SM1 was more like that found for strain CN 2000 .

\section{DISCUSSION}

In 1958 Yoneda \& Ishihara concluded that iron exerted a 'distinct influence not only on the liberation of toxin but also on the pyruvate metabolism of the organism'. From the results presented in the present paper it seems clear that no such influence was exerted on pyruvate metabolism when strain $\mathrm{CN} 2000$ of Corynebacterium diphtheriae was grown in aerated submerged culture. The SM 1 strain (the one used by the Japanese workers) did appear to give a change in pyruvic acid production in the presence of iron but when the toxin titres were $100 \mathrm{Lf} / \mathrm{ml}$. for the control culture and $0 \mathrm{Lf} / \mathrm{ml}$. for the one containing iron, the final pyruvic acid concentrations were 94 and $271 \mu \mathrm{g} . / \mathrm{ml}$. respectively. Yoneda \& Ishihara on the other hand found that as the toxin titre fell from 60 to $0 \mathrm{Lf} / \mathrm{ml}$. the pyruvic acid concentration fell from 220 to $11 \mu \mathrm{g} . / \mathrm{ml}$.; thus a serious difference exists between the two sets of results. The differences in the two methods of cultivation must be borne in mind, but regardless of this, the present results with the SM 1 strain, together with the fact that the pyruvic acid metabolism of strain CN2000 was virtually unaffected by the presence of $3 \mu \mathrm{g}$. Fe $/ \mathrm{ml}$., seem to rule out the possibility that toxin and pyruvic acid production are necessarily closely linked.

The rapid decrease in lactic acid concentration and corresponding increase in pyruvic acid shown in Fig. 2 suggest the presence in $C$. diphtheriae strain CN2000 of a powerful lactic acid dehydrogenase. After incubation for $12 \mathrm{hr}$. the cultures contain $c .10^{8}-10^{9}$ viable organisms $/ \mathrm{ml}$. compared with $c .10^{10}$ viable organisms $/ \mathrm{ml}$. after $24 \mathrm{hr}$., so that the production of the high yields of pyruvic acid has been brought about by relatively few organisms. The cause of the change from production to disappearance of pyruvic acid is obscure, but it may be that shortage of oxygen, which has already been suggested as the factor which limits the growth rate (Edwards, 1960), is responsible for the $12 \mathrm{hr}$. culture beginning to reduce some pyruvic acid to lactic acid.

I wish to thank Dr C. G. Pope for discussions during the course of this work and Miss V. Gooch and Mr H. R. Hazelton for their technical assistance. 


\section{REFERENCES}

Barker, S. B. \& Summerson, W. H. (1941). The colorimetric determination of lactic acid in biological material. J. biol. Chem. 138, 535.

Cavaluini, D. \& Frontali, M. (1954). Determination of keto-acids by paper partition chromatography. Biochim. biophys. Acta, 13, 439.

Cavaluini, D. \& Mandovi, B. (1957). The use of formaldehyde to avoid artefacts in the chromatographic determination of keto acids. Clin. Chim. Acta, 2, 312.

EDwaRDS, D. C. (1960). The growth and toxin production of Corynebacterium diphtheriae in submerged culture. J. gen. Microbiol. 22, 698.

Edwards, D. C. \& Seamer, P. A. (1960). The uptake of iron by Corynebacterium diphtheriae growing in submerged culture. J. gen. Microbiol. $22,705$.

El Hawary, M. F. S. \& Thomson, R. H. S. (1953). Separation and estimation of blood keto acids by paper chromatography. Biochem. J. 53, 340.

Glenny, A. T. \& Okelx, C. C. (1924). The titration of diphtheria toxin and antitoxin by flocculation methods. J. Path. Bact. 27, 187.

JäNES, L. (1954). Studies on the terminal oxidative reaction patterns of the carbohydrate metabolism of Corynebacterium diphtheriae. Ann. Acad. Sci. fenn. (Ser. A, sec. 2), 61, 1.

Linggood, F. V., Matthews, A. C., Pinfield, S., Pope, C. G. \& Sharland, T. R. (1955). Production of diphtheria toxin in submerged culture. Nature, Lond. 176, 1128.

Pope, C. G. \& Smrth, M. L. (1932). The routine preparation of diphtheria toxin of high value. J. Path. Bact. 35, 573.

Ramon, G. (1922). Floculation dans un mélange neutre de toxin-antitoxine diphtériques. C.R. Soc. Biol., Paris, 86, 661.

Ramon, G., Pochon, J. \& Amoureux, G. (1941). La production à l'aide d'un nouveau milieu de culture à base de digestion papainique des toxines microbiennes et specialement des toxines diphtériques et staphylococciques destinées à la preparation des anatoxines correspondantes. C.R. Soc. Biol., Paris, 135, 1502.

Yoneda, M. \& Ishinara, H. (1958). Accumulation of $\alpha$-alanine and of pyruvate in diphtherial culture filtrate and its relation to iron deficiency of medium. Nature, Lond. 181, 272. 